\title{
Crossability among Five Cassava (Manihot esculenta Crantz) Varieties
}

\author{
Ukwu NU and Olasanmi B* \\ Department of Agronomy, University of Ibadan, Nigeria \\ *Corresponding author: Olasanmi B*, Department of Agronomy, University of Ibadan, Nigeria
}

\begin{abstract}
Submission: 眥 May 17, 2018; Published: 眥 June 26, 2018
Abstract
Controlled crosses were carried out to determine crossability among five selected cassava varieties in terms of seed set per cross and influence
of maternal inheritance on seed set in cassava. The experiment was carried out at the Teaching and Research Farm of the Department of Agronomy,
University of Ibadan Oyo State, Nigeria. Three yellow root varieties (IITA-TMS-I011412, IITA-TMS-I011368 and IITA-TMS-I070539) selected for their
high $\beta$-carotene content and two white root varieties (IITA-TMS-I30752 and COB-7-25) selected for their high dry matter content and acceptable plant
architecture among subsistence farmers were crossed in a reciprocal diallel design with no selfing. Fourteen hybrid populations were developed and
data obtained were analyzed using t-Test and simple linear correlation. The result showed that genotype and maternal inheritance influenced seed
set in cassava. The cross IITA-TMS-I011368 x IITA-TMS-I011412 gave the highest seed set percentage (57.1) and the two parents were the best female
and male parents, respectively. This was followed by IITA-TMS-I30752 x IITA-TMS-I011412 (39.8\%), IITA-TMS-I011368 x IITA-TMS-I070539 (26.5\%),
IITA-TMS-I070539 x IITA-TMS-I011412 (24.9\%) and IITA-TMS-I30752 x IITA-TMS-I011368 (24.1\%). Reciprocal differences were observed for crosses
between IITA-TMS-I30752 and IITA-TMS-I011412; IITA-TMS-I011412 and IITA-TMS-I011368; IITA-TMS-I011412 and COB-7-25 which suggests that
seed set in cassava is influenced by cytoplasmic genes which are transmitted exclusively by the maternal parent. The best female and male parents
(IITA-TMS-I011368 and IITA-TMS-I011412) in terms of percentage seed set in this study are good candidates as parents to generate large populations
in breeding for high carotene content in cassava.

Abstract
Controlled crosses were carried out to determine crossability among five selected cassava varieties in terms of seed set per cross and influence
of maternal inheritance on seed set in cassava. The experiment was carried out at the Teaching and Research Farm of the Department of Agronomy,
University of Ibadan Oyo State, Nigeria. Three yellow root varieties (IITA-TMS-I011412, IITA-TMS-I011368 and IITA-TMS-I070539) selected for their
high $\beta$-carotene content and two white root varieties (IITA-TMS-I30752 and COB-7-25) selected for their high dry matter content and acceptable plant
architecture among subsistence farmers were crossed in a reciprocal diallel design with no selfing. Fourteen hybrid populations were developed and
data obtained were analyzed using t-Test and simple linear correlation. The result showed that genotype and maternal inheritance influenced seed
set in cassava. The cross IITA-TMS-I011368 x IITA-TMS-I011412 gave the highest seed set percentage (57.1) and the two parents were the best female
and male parents, respectively. This was followed by IITA-TMS-I30752 x IITA-TMS-I011412 (39.8\%), IITA-TMS-I011368 x IITA-TMS-I070539 (26.5\%),
IITA-TMS-I070539 x IITA-TMS-I011412 (24.9\%) and IITA-TMS-I30752 x IITA-TMS-I011368 (24.1\%). Reciprocal differences were observed for crosses
between IITA-TMS-I30752 and IITA-TMS-I011412; IITA-TMS-I011412 and IITA-TMS-I011368; IITA-TMS-I011412 and COB-7-25 which suggests that
seed set in cassava is influenced by cytoplasmic genes which are transmitted exclusively by the maternal parent. The best female and male parents
(IITA-TMS-I011368 and IITA-TMS-I011412) in terms of percentage seed set in this study are good candidates as parents to generate large populations
in breeding for high carotene content in cassava.

Abstract
Controlled crosses were carried out to determine crossability among five selected cassava varieties in terms of seed set per cross and influence
of maternal inheritance on seed set in cassava. The experiment was carried out at the Teaching and Research Farm of the Department of Agronomy,
University of Ibadan Oyo State, Nigeria. Three yellow root varieties (IITA-TMS-I011412, IITA-TMS-I011368 and IITA-TMS-I070539) selected for their
high $\beta$-carotene content and two white root varieties (IITA-TMS-I30752 and COB-7-25) selected for their high dry matter content and acceptable plant
architecture among subsistence farmers were crossed in a reciprocal diallel design with no selfing. Fourteen hybrid populations were developed and
data obtained were analyzed using t-Test and simple linear correlation. The result showed that genotype and maternal inheritance influenced seed
set in cassava. The cross IITA-TMS-I011368 x IITA-TMS-I011412 gave the highest seed set percentage (57.1) and the two parents were the best female
and male parents, respectively. This was followed by IITA-TMS-I30752 x IITA-TMS-I011412 (39.8\%), IITA-TMS-I011368 x IITA-TMS-I070539 (26.5\%),
IITA-TMS-I070539 x IITA-TMS-I011412 (24.9\%) and IITA-TMS-I30752 x IITA-TMS-I011368 (24.1\%). Reciprocal differences were observed for crosses
between IITA-TMS-I30752 and IITA-TMS-I011412; IITA-TMS-I011412 and IITA-TMS-I011368; IITA-TMS-I011412 and COB-7-25 which suggests that
seed set in cassava is influenced by cytoplasmic genes which are transmitted exclusively by the maternal parent. The best female and male parents
(IITA-TMS-I011368 and IITA-TMS-I011412) in terms of percentage seed set in this study are good candidates as parents to generate large populations
in breeding for high carotene content in cassava.

Abstract
Controlled crosses were carried out to determine crossability among five selected cassava varieties in terms of seed set per cross and influence
of maternal inheritance on seed set in cassava. The experiment was carried out at the Teaching and Research Farm of the Department of Agronomy,
University of Ibadan Oyo State, Nigeria. Three yellow root varieties (IITA-TMS-I011412, IITA-TMS-I011368 and IITA-TMS-I070539) selected for their
high $\beta$-carotene content and two white root varieties (IITA-TMS-I30752 and COB-7-25) selected for their high dry matter content and acceptable plant
architecture among subsistence farmers were crossed in a reciprocal diallel design with no selfing. Fourteen hybrid populations were developed and
data obtained were analyzed using t-Test and simple linear correlation. The result showed that genotype and maternal inheritance influenced seed
set in cassava. The cross IITA-TMS-I011368 x IITA-TMS-I011412 gave the highest seed set percentage (57.1) and the two parents were the best female
and male parents, respectively. This was followed by IITA-TMS-I30752 x IITA-TMS-I011412 (39.8\%), IITA-TMS-I011368 x IITA-TMS-I070539 (26.5\%),
IITA-TMS-I070539 x IITA-TMS-I011412 (24.9\%) and IITA-TMS-I30752 x IITA-TMS-I011368 (24.1\%). Reciprocal differences were observed for crosses
between IITA-TMS-I30752 and IITA-TMS-I011412; IITA-TMS-I011412 and IITA-TMS-I011368; IITA-TMS-I011412 and COB-7-25 which suggests that
seed set in cassava is influenced by cytoplasmic genes which are transmitted exclusively by the maternal parent. The best female and male parents
(IITA-TMS-I011368 and IITA-TMS-I011412) in terms of percentage seed set in this study are good candidates as parents to generate large populations
in breeding for high carotene content in cassava.

Abstract
Controlled crosses were carried out to determine crossability among five selected cassava varieties in terms of seed set per cross and influence
of maternal inheritance on seed set in cassava. The experiment was carried out at the Teaching and Research Farm of the Department of Agronomy,
University of Ibadan Oyo State, Nigeria. Three yellow root varieties (IITA-TMS-I011412, IITA-TMS-I011368 and IITA-TMS-I070539) selected for their
high $\beta$-carotene content and two white root varieties (IITA-TMS-I30752 and COB-7-25) selected for their high dry matter content and acceptable plant
architecture among subsistence farmers were crossed in a reciprocal diallel design with no selfing. Fourteen hybrid populations were developed and
data obtained were analyzed using t-Test and simple linear correlation. The result showed that genotype and maternal inheritance influenced seed
set in cassava. The cross IITA-TMS-I011368 x IITA-TMS-I011412 gave the highest seed set percentage (57.1) and the two parents were the best female
and male parents, respectively. This was followed by IITA-TMS-I30752 x IITA-TMS-I011412 (39.8\%), IITA-TMS-I011368 x IITA-TMS-I070539 (26.5\%),
IITA-TMS-I070539 x IITA-TMS-I011412 (24.9\%) and IITA-TMS-I30752 x IITA-TMS-I011368 (24.1\%). Reciprocal differences were observed for crosses
between IITA-TMS-I30752 and IITA-TMS-I011412; IITA-TMS-I011412 and IITA-TMS-I011368; IITA-TMS-I011412 and COB-7-25 which suggests that
seed set in cassava is influenced by cytoplasmic genes which are transmitted exclusively by the maternal parent. The best female and male parents
(IITA-TMS-I011368 and IITA-TMS-I011412) in terms of percentage seed set in this study are good candidates as parents to generate large populations
in breeding for high carotene content in cassava.

Abstract
Controlled crosses were carried out to determine crossability among five selected cassava varieties in terms of seed set per cross and influence
of maternal inheritance on seed set in cassava. The experiment was carried out at the Teaching and Research Farm of the Department of Agronomy,
University of Ibadan Oyo State, Nigeria. Three yellow root varieties (IITA-TMS-I011412, IITA-TMS-I011368 and IITA-TMS-I070539) selected for their
high $\beta$-carotene content and two white root varieties (IITA-TMS-I30752 and COB-7-25) selected for their high dry matter content and acceptable plant
architecture among subsistence farmers were crossed in a reciprocal diallel design with no selfing. Fourteen hybrid populations were developed and
data obtained were analyzed using t-Test and simple linear correlation. The result showed that genotype and maternal inheritance influenced seed
set in cassava. The cross IITA-TMS-I011368 x IITA-TMS-I011412 gave the highest seed set percentage (57.1) and the two parents were the best female
and male parents, respectively. This was followed by IITA-TMS-I30752 x IITA-TMS-I011412 (39.8\%), IITA-TMS-I011368 x IITA-TMS-I070539 (26.5\%),
IITA-TMS-I070539 x IITA-TMS-I011412 (24.9\%) and IITA-TMS-I30752 x IITA-TMS-I011368 (24.1\%). Reciprocal differences were observed for crosses
between IITA-TMS-I30752 and IITA-TMS-I011412; IITA-TMS-I011412 and IITA-TMS-I011368; IITA-TMS-I011412 and COB-7-25 which suggests that
seed set in cassava is influenced by cytoplasmic genes which are transmitted exclusively by the maternal parent. The best female and male parents
(IITA-TMS-I011368 and IITA-TMS-I011412) in terms of percentage seed set in this study are good candidates as parents to generate large populations
in breeding for high carotene content in cassava.

Abstract
Controlled crosses were carried out to determine crossability among five selected cassava varieties in terms of seed set per cross and influence
of maternal inheritance on seed set in cassava. The experiment was carried out at the Teaching and Research Farm of the Department of Agronomy,
University of Ibadan Oyo State, Nigeria. Three yellow root varieties (IITA-TMS-I011412, IITA-TMS-I011368 and IITA-TMS-I070539) selected for their
high $\beta$-carotene content and two white root varieties (IITA-TMS-I30752 and COB-7-25) selected for their high dry matter content and acceptable plant
architecture among subsistence farmers were crossed in a reciprocal diallel design with no selfing. Fourteen hybrid populations were developed and
data obtained were analyzed using t-Test and simple linear correlation. The result showed that genotype and maternal inheritance influenced seed
set in cassava. The cross IITA-TMS-I011368 x IITA-TMS-I011412 gave the highest seed set percentage (57.1) and the two parents were the best female
and male parents, respectively. This was followed by IITA-TMS-I30752 x IITA-TMS-I011412 (39.8\%), IITA-TMS-I011368 x IITA-TMS-I070539 (26.5\%),
IITA-TMS-I070539 x IITA-TMS-I011412 (24.9\%) and IITA-TMS-I30752 x IITA-TMS-I011368 (24.1\%). Reciprocal differences were observed for crosses
between IITA-TMS-I30752 and IITA-TMS-I011412; IITA-TMS-I011412 and IITA-TMS-I011368; IITA-TMS-I011412 and COB-7-25 which suggests that
seed set in cassava is influenced by cytoplasmic genes which are transmitted exclusively by the maternal parent. The best female and male parents
(IITA-TMS-I011368 and IITA-TMS-I011412) in terms of percentage seed set in this study are good candidates as parents to generate large populations
in breeding for high carotene content in cassava.

Abstract
Controlled crosses were carried out to determine crossability among five selected cassava varieties in terms of seed set per cross and influence
of maternal inheritance on seed set in cassava. The experiment was carried out at the Teaching and Research Farm of the Department of Agronomy,
University of Ibadan Oyo State, Nigeria. Three yellow root varieties (IITA-TMS-I011412, IITA-TMS-I011368 and IITA-TMS-I070539) selected for their
high $\beta$-carotene content and two white root varieties (IITA-TMS-I30752 and COB-7-25) selected for their high dry matter content and acceptable plant
architecture among subsistence farmers were crossed in a reciprocal diallel design with no selfing. Fourteen hybrid populations were developed and
data obtained were analyzed using t-Test and simple linear correlation. The result showed that genotype and maternal inheritance influenced seed
set in cassava. The cross IITA-TMS-I011368 x IITA-TMS-I011412 gave the highest seed set percentage (57.1) and the two parents were the best female
and male parents, respectively. This was followed by IITA-TMS-I30752 x IITA-TMS-I011412 (39.8\%), IITA-TMS-I011368 x IITA-TMS-I070539 (26.5\%),
IITA-TMS-I070539 x IITA-TMS-I011412 (24.9\%) and IITA-TMS-I30752 x IITA-TMS-I011368 (24.1\%). Reciprocal differences were observed for crosses
between IITA-TMS-I30752 and IITA-TMS-I011412; IITA-TMS-I011412 and IITA-TMS-I011368; IITA-TMS-I011412 and COB-7-25 which suggests that
seed set in cassava is influenced by cytoplasmic genes which are transmitted exclusively by the maternal parent. The best female and male parents
(IITA-TMS-I011368 and IITA-TMS-I011412) in terms of percentage seed set in this study are good candidates as parents to generate large populations
in breeding for high carotene content in cassava.

Abstract
Controlled crosses were carried out to determine crossability among five selected cassava varieties in terms of seed set per cross and influence
of maternal inheritance on seed set in cassava. The experiment was carried out at the Teaching and Research Farm of the Department of Agronomy,
University of Ibadan Oyo State, Nigeria. Three yellow root varieties (IITA-TMS-I011412, IITA-TMS-I011368 and IITA-TMS-I070539) selected for their
high $\beta$-carotene content and two white root varieties (IITA-TMS-I30752 and COB-7-25) selected for their high dry matter content and acceptable plant
architecture among subsistence farmers were crossed in a reciprocal diallel design with no selfing. Fourteen hybrid populations were developed and
data obtained were analyzed using t-Test and simple linear correlation. The result showed that genotype and maternal inheritance influenced seed
set in cassava. The cross IITA-TMS-I011368 x IITA-TMS-I011412 gave the highest seed set percentage (57.1) and the two parents were the best female
and male parents, respectively. This was followed by IITA-TMS-I30752 x IITA-TMS-I011412 (39.8\%), IITA-TMS-I011368 x IITA-TMS-I070539 (26.5\%),
IITA-TMS-I070539 x IITA-TMS-I011412 (24.9\%) and IITA-TMS-I30752 x IITA-TMS-I011368 (24.1\%). Reciprocal differences were observed for crosses
between IITA-TMS-I30752 and IITA-TMS-I011412; IITA-TMS-I011412 and IITA-TMS-I011368; IITA-TMS-I011412 and COB-7-25 which suggests that
seed set in cassava is influenced by cytoplasmic genes which are transmitted exclusively by the maternal parent. The best female and male parents
(IITA-TMS-I011368 and IITA-TMS-I011412) in terms of percentage seed set in this study are good candidates as parents to generate large populations
in breeding for high carotene content in cassava.

Abstract
Controlled crosses were carried out to determine crossability among five selected cassava varieties in terms of seed set per cross and influence
of maternal inheritance on seed set in cassava. The experiment was carried out at the Teaching and Research Farm of the Department of Agronomy,
University of Ibadan Oyo State, Nigeria. Three yellow root varieties (IITA-TMS-I011412, IITA-TMS-I011368 and IITA-TMS-I070539) selected for their
high $\beta$-carotene content and two white root varieties (IITA-TMS-I30752 and COB-7-25) selected for their high dry matter content and acceptable plant
architecture among subsistence farmers were crossed in a reciprocal diallel design with no selfing. Fourteen hybrid populations were developed and
data obtained were analyzed using t-Test and simple linear correlation. The result showed that genotype and maternal inheritance influenced seed
set in cassava. The cross IITA-TMS-I011368 x IITA-TMS-I011412 gave the highest seed set percentage (57.1) and the two parents were the best female
and male parents, respectively. This was followed by IITA-TMS-I30752 x IITA-TMS-I011412 (39.8\%), IITA-TMS-I011368 x IITA-TMS-I070539 (26.5\%),
IITA-TMS-I070539 x IITA-TMS-I011412 (24.9\%) and IITA-TMS-I30752 x IITA-TMS-I011368 (24.1\%). Reciprocal differences were observed for crosses
between IITA-TMS-I30752 and IITA-TMS-I011412; IITA-TMS-I011412 and IITA-TMS-I011368; IITA-TMS-I011412 and COB-7-25 which suggests that
seed set in cassava is influenced by cytoplasmic genes which are transmitted exclusively by the maternal parent. The best female and male parents
(IITA-TMS-I011368 and IITA-TMS-I011412) in terms of percentage seed set in this study are good candidates as parents to generate large populations
in breeding for high carotene content in cassava.

Abstract
Controlled crosses were carried out to determine crossability among five selected cassava varieties in terms of seed set per cross and influence
of maternal inheritance on seed set in cassava. The experiment was carried out at the Teaching and Research Farm of the Department of Agronomy,
University of Ibadan Oyo State, Nigeria. Three yellow root varieties (IITA-TMS-I011412, IITA-TMS-I011368 and IITA-TMS-I070539) selected for their
high $\beta$-carotene content and two white root varieties (IITA-TMS-I30752 and COB-7-25) selected for their high dry matter content and acceptable plant
architecture among subsistence farmers were crossed in a reciprocal diallel design with no selfing. Fourteen hybrid populations were developed and
data obtained were analyzed using t-Test and simple linear correlation. The result showed that genotype and maternal inheritance influenced seed
set in cassava. The cross IITA-TMS-I011368 x IITA-TMS-I011412 gave the highest seed set percentage (57.1) and the two parents were the best female
and male parents, respectively. This was followed by IITA-TMS-I30752 x IITA-TMS-I011412 (39.8\%), IITA-TMS-I011368 x IITA-TMS-I070539 (26.5\%),
IITA-TMS-I070539 x IITA-TMS-I011412 (24.9\%) and IITA-TMS-I30752 x IITA-TMS-I011368 (24.1\%). Reciprocal differences were observed for crosses
between IITA-TMS-I30752 and IITA-TMS-I011412; IITA-TMS-I011412 and IITA-TMS-I011368; IITA-TMS-I011412 and COB-7-25 which suggests that
seed set in cassava is influenced by cytoplasmic genes which are transmitted exclusively by the maternal parent. The best female and male parents
(IITA-TMS-I011368 and IITA-TMS-I011412) in terms of percentage seed set in this study are good candidates as parents to generate large populations
in breeding for high carotene content in cassava.

Abstract
Controlled crosses were carried out to determine crossability among five selected cassava varieties in terms of seed set per cross and influence
of maternal inheritance on seed set in cassava. The experiment was carried out at the Teaching and Research Farm of the Department of Agronomy,
University of Ibadan Oyo State, Nigeria. Three yellow root varieties (IITA-TMS-I011412, IITA-TMS-I011368 and IITA-TMS-I070539) selected for their
high $\beta$-carotene content and two white root varieties (IITA-TMS-I30752 and COB-7-25) selected for their high dry matter content and acceptable plant
architecture among subsistence farmers were crossed in a reciprocal diallel design with no selfing. Fourteen hybrid populations were developed and
data obtained were analyzed using t-Test and simple linear correlation. The result showed that genotype and maternal inheritance influenced seed
set in cassava. The cross IITA-TMS-I011368 x IITA-TMS-I011412 gave the highest seed set percentage (57.1) and the two parents were the best female
and male parents, respectively. This was followed by IITA-TMS-I30752 x IITA-TMS-I011412 (39.8\%), IITA-TMS-I011368 x IITA-TMS-I070539 (26.5\%),
IITA-TMS-I070539 x IITA-TMS-I011412 (24.9\%) and IITA-TMS-I30752 x IITA-TMS-I011368 (24.1\%). Reciprocal differences were observed for crosses
between IITA-TMS-I30752 and IITA-TMS-I011412; IITA-TMS-I011412 and IITA-TMS-I011368; IITA-TMS-I011412 and COB-7-25 which suggests that
seed set in cassava is influenced by cytoplasmic genes which are transmitted exclusively by the maternal parent. The best female and male parents
(IITA-TMS-I011368 and IITA-TMS-I011412) in terms of percentage seed set in this study are good candidates as parents to generate large populations
in breeding for high carotene content in cassava.

Abstract
Controlled crosses were carried out to determine crossability among five selected cassava varieties in terms of seed set per cross and influence
of maternal inheritance on seed set in cassava. The experiment was carried out at the Teaching and Research Farm of the Department of Agronomy,
University of Ibadan Oyo State, Nigeria. Three yellow root varieties (IITA-TMS-I011412, IITA-TMS-I011368 and IITA-TMS-I070539) selected for their
high $\beta$-carotene content and two white root varieties (IITA-TMS-I30752 and COB-7-25) selected for their high dry matter content and acceptable plant
architecture among subsistence farmers were crossed in a reciprocal diallel design with no selfing. Fourteen hybrid populations were developed and
data obtained were analyzed using t-Test and simple linear correlation. The result showed that genotype and maternal inheritance influenced seed
set in cassava. The cross IITA-TMS-I011368 x IITA-TMS-I011412 gave the highest seed set percentage (57.1) and the two parents were the best female
and male parents, respectively. This was followed by IITA-TMS-I30752 x IITA-TMS-I011412 (39.8\%), IITA-TMS-I011368 x IITA-TMS-I070539 (26.5\%),
IITA-TMS-I070539 x IITA-TMS-I011412 (24.9\%) and IITA-TMS-I30752 x IITA-TMS-I011368 (24.1\%). Reciprocal differences were observed for crosses
between IITA-TMS-I30752 and IITA-TMS-I011412; IITA-TMS-I011412 and IITA-TMS-I011368; IITA-TMS-I011412 and COB-7-25 which suggests that
seed set in cassava is influenced by cytoplasmic genes which are transmitted exclusively by the maternal parent. The best female and male parents
(IITA-TMS-I011368 and IITA-TMS-I011412) in terms of percentage seed set in this study are good candidates as parents to generate large populations
in breeding for high carotene content in cassava.

Abstract
Controlled crosses were carried out to determine crossability among five selected cassava varieties in terms of seed set per cross and influence
of maternal inheritance on seed set in cassava. The experiment was carried out at the Teaching and Research Farm of the Department of Agronomy,
University of Ibadan Oyo State, Nigeria. Three yellow root varieties (IITA-TMS-I011412, IITA-TMS-I011368 and IITA-TMS-I070539) selected for their
high $\beta$-carotene content and two white root varieties (IITA-TMS-I30752 and COB-7-25) selected for their high dry matter content and acceptable plant
architecture among subsistence farmers were crossed in a reciprocal diallel design with no selfing. Fourteen hybrid populations were developed and
data obtained were analyzed using t-Test and simple linear correlation. The result showed that genotype and maternal inheritance influenced seed
set in cassava. The cross IITA-TMS-I011368 x IITA-TMS-I011412 gave the highest seed set percentage (57.1) and the two parents were the best female
and male parents, respectively. This was followed by IITA-TMS-I30752 x IITA-TMS-I011412 (39.8\%), IITA-TMS-I011368 x IITA-TMS-I070539 (26.5\%),
IITA-TMS-I070539 x IITA-TMS-I011412 (24.9\%) and IITA-TMS-I30752 x IITA-TMS-I011368 (24.1\%). Reciprocal differences were observed for crosses
between IITA-TMS-I30752 and IITA-TMS-I011412; IITA-TMS-I011412 and IITA-TMS-I011368; IITA-TMS-I011412 and COB-7-25 which suggests that
seed set in cassava is influenced by cytoplasmic genes which are transmitted exclusively by the maternal parent. The best female and male parents
(IITA-TMS-I011368 and IITA-TMS-I011412) in terms of percentage seed set in this study are good candidates as parents to generate large populations
in breeding for high carotene content in cassava.
\end{abstract}

Keywords: $\beta$-carotene content; Hybridization; Maternal inheritance; Percentage seed set; Plant architecture

\section{Introduction}

Cassava (Manihot esculenta Crantz) is a short-lived perennial shrub which is grown globally in areas where average annual temperature exceeds $18^{\circ} \mathrm{C}[1]$. It is widely cultivated with annual global production of about 276.7 million metric tons [2]. Nigeria is the largest producer with annual production of about 54.8 million metric tons [3]. This wide cultivation is favoured by its ability to thrive in degraded soils and produce acceptable yields even when grown in unfavorable environmental conditions [4]. Commercial propagation is done by means of vegetative stem cuttings while botanical seeds are mostly used in breeding programmes to generate new genetic variation [5].

Cassava ranks fourth as the most important basic food after rice, wheat and maize [6]. It is a fundamental component in the diet of millions of people [6], which is evident in the per capita consumption of over $200 \mathrm{~kg} /$ year in North central and Southern Nigeria [7]. The starchy roots are very rich in calories, supplying over $100 \mathrm{kcal}$ to about 570 million people [8], but are lacking in other major food elements such as proteins, fats and important micronutrients like pro-vitamin $\mathrm{A}$, iron and zinc [9]. A great majority of people who depend on cassava as their major staple food are therefore deficient in vitamin [10]. Encouragingly, carotenoids which are the precursors of vitamin A have been found in substantial amount in yellow-root cassava varieties and have been reported to be responsible for the yellow to orange coloration of the storage root flesh of some varieties [11].

Hybridization is a major tool in combining diverged genomes into one nucleus [12] and has been the major source of genetic recombination in cassava species. Successful pollination in cassava depends on pollen maturity, quality or freshness and timing of pollination among other factors [13]. However, embarking on cassava breeding program without prior information on the degree of crossability among selected genotypes could result in cross incompatibility, high fruit abortion rate, wastage of resources and loss of valuable time and efforts. Therefore, success of a cassava breeding programme depends on the compatibility of selected parents to generate new populations. This study was carried out to determine crossability among some yellow- and white-root cassava varieties in terms of seed set per cross and find out the influence of maternal inheritance on seed set in cassava.

\section{Materials and Methods}

\section{Evaluation site and parent materials}

The experiment was carried out at the Teaching and Research Farm (longitude $3^{\circ} 45^{\prime} \mathrm{E}$ and latitude $7^{\circ} 27^{\prime} \mathrm{N}$ ) of Department 
of Agronomy, University of Ibadan, Oyo State, Nigeria. Parent materials consisted of three improved yellow-root cassava varieties (IITA-TMS-I011412, IITA-TMS-I011368 and IITA-TMS-I070539) selected for their high $\beta$-carotene content and two white-root cassava varieties (IITA-TMS-I30572 and COB-7-25) selected for their high dry matter content and acceptable plant architecture among subsistence farmers. Stem cuttings measuring $25 \mathrm{~cm}$ each were obtained from mature stems and were dipped in a bowl containing a solution of $10 \mathrm{ml}$ AFCOT (an emulsifiable concentrate insecticide containing $20 \%$ chlorpyriphos) mixed with 10 litres of water for five minutes to prevent attack by termites. The land was ploughed twice and ridged manually at $1 \mathrm{~m}$ apart across the slope to minimize erosion problem. The stem cuttings were planted in plots arranged using Randomized Complete Block Design (RCBD) and the experiment was replicated three times. Twenty stem cuttings were planted in each plot measuring $20 \mathrm{~m}^{2}$ at a spacing of $1 \mathrm{~m} \times 1 \mathrm{~m}$. Manual weeding was carried out one month after planting (MAP) using hoe. Subsequently, post-emergence herbicide (glyphosate) was used to control the weeds after the crops have been firmly established.

\section{Pollination}

Controlled pollination was carried out using a reciprocal diallel design following Griffing's procedure (Model I, Method III) of 1958 (Table 1). On each day pollination was carried out, mature female flowers were covered with cloth bags measuring $17 \mathrm{~cm} \times 21 \mathrm{~cm}$ in the early hours of the morning between 8:00 and 10:00am to prevent stray pollination. Female flowers that were already open on each raceme at the time of covering were carefully emasculated. Immature female flowers that were yet to open at the time of pollination were also emasculated so as to ensure that all the fruits resulting from such raceme are from controlled pollination. Mature male flowers were collected between the hours of 10:00 and 11:00 am shortly before opening and kept in cloth bags under shade until the time of pollination.

Table 1: Cross combinations among five cassava varieties used as parents in hybridization study in Ibadan in 2015.

\begin{tabular}{|c|c|c|}
\hline Populations & Female Parent & Male Parent \\
\hline UIC-1 & IITA-TMS-I011412 & IITA-TMS-I011368 \\
\hline UIC-2 & IITA-TMS-I011412 & IITA-TMS-I070539 \\
\hline UIC-3 & IITA-TMS-I011412 & СОВ-7-25 \\
\hline UIC-4 & IITA-TMS-I011412 & IITA-TMS-I30572 \\
\hline UIC-5 & IITA-TMS-I070539 & IITA-TMS-I011368 \\
\hline UIC-6 & IITA-TMS-I070539 & IITA-TMS-I30572 \\
\hline UIC-7 & COB-7-25 & IITA-TMS-I070539 \\
\hline UIC-8 & IITA-TMS-I011368 & IITA-TMS-I30572 \\
\hline UIC-9 & COB-7-25 & IITA-TMS-I011368 \\
\hline UIC-10 & IITA-TMS-I30572 & COB-7-25 \\
\hline UIC-11 & IITA-TMS-I011368 & IITA-TMS-I011412 \\
\hline UIC-12 & IITA-TMS-I070539 & IITA-TMS-I011412 \\
\hline UIC-13 & COB-7-25 & IITA-TMS-I011412 \\
\hline UIC-14 & IITA-TMS-I30572 & IITA-TMS-I011412 \\
\hline UIC-15 & IITA-TMS-I011368 & IITA-TMS-I070539 \\
\hline UIC-16 & IITA-TMS-I30572 & IITA-TMS-I070539 \\
\hline UIC-17 & IITA-TMS-I070539 & COB-7-25 \\
\hline UIC-18 & IITA-TMS-I30572 & IITA-TMS-I011368 \\
\hline UIC-19 & IITA-TMS-I011368 & СOB-7-25 \\
\hline UIC-20 & COB-7-25 & IITA-TMS-I30572 \\
\hline
\end{tabular}

UIC = University of Ibadan Cassava.

Pollination was carried out between 1 and $5 \mathrm{pm}$ daily using one male flower to pollinate between 1 and 3 female flowers and the flowers were left open afterwards. Each pollinated raceme was labelled with a tag indicating the cross combination, number of flowers pollinated and the date of pollination. The number of flowers pollinated per cross combination was recorded daily. Due to the explosive nature of fruit dehiscence in cassava species, developing young fruits were enclosed in cloth bags one month after pollination so as to retain dropped mature fruits and dehisced seeds. There were no losses from insect infestation as the fruits were protected by the bag. The seeds were collected about three months after pollination, sorted, dried and bulked for each cross combination. The scheme used in the development of the hybrid populations is shown in Figure 1. 


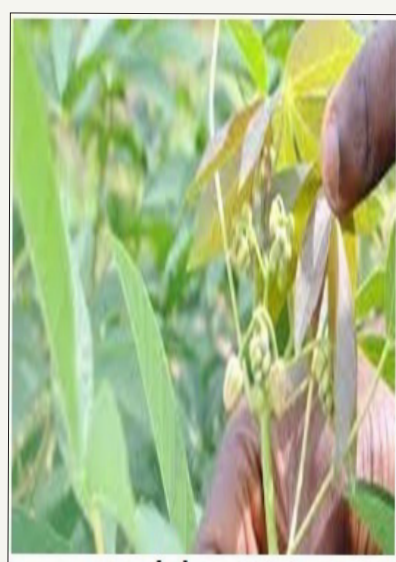

(a)

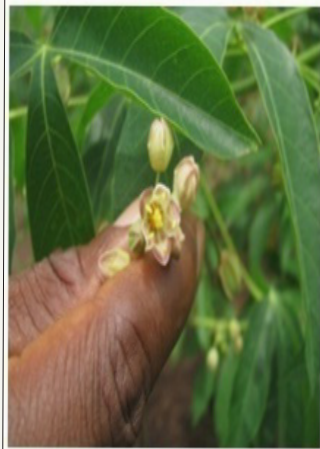

(d)

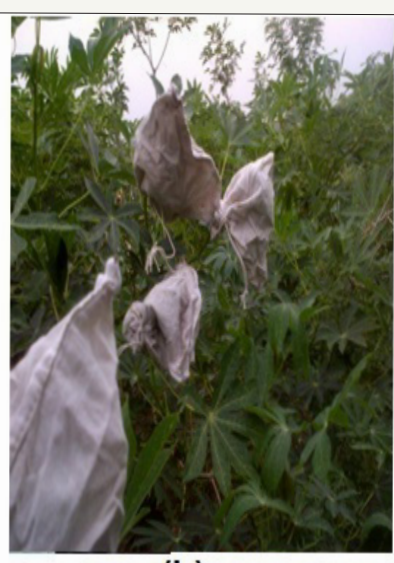

(b)

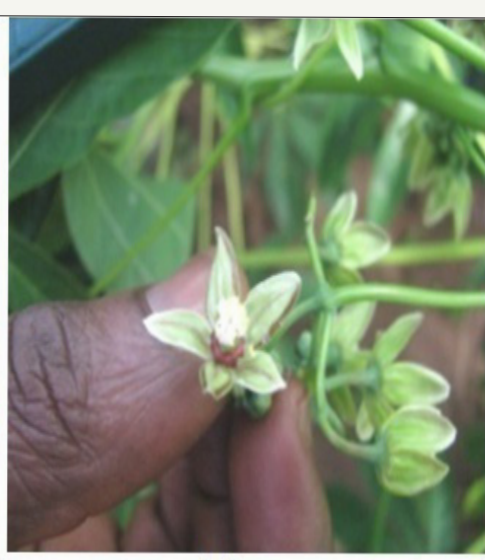

(c)

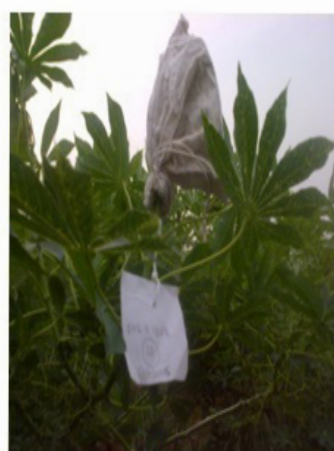

(f)

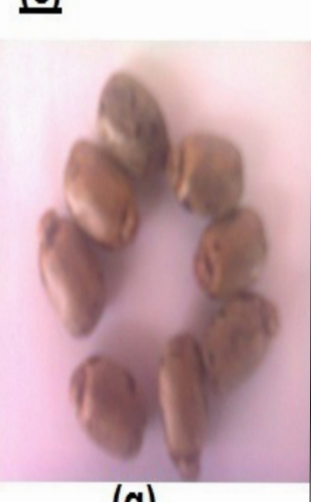

(g)

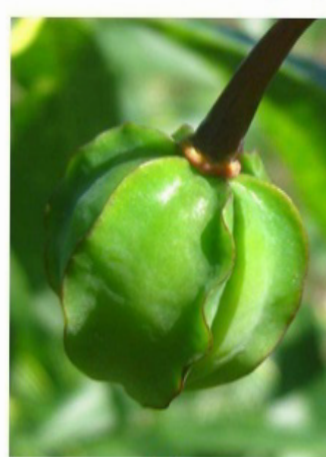

(e)

Figure 1: Schematic representation of the steps employed in the development of the hybrid populations.

(a) Mature female flowers (b) Covering of mature female flowers (c) Opened female flower (d) Mature male flower (e) Developing young fruits after pollination (f) Covered fruits 1 month after pollination (g) Botanical seeds.

\section{Statistical analysis}

Data collected on number of flowers pollinated and number of seeds collected per cross combination were used to estimate the expected number of seeds and percentage seed set as shown below:

Expected number of seeds $=$ number of flowers pollinated $\times 3$ fruit).

(Cassava fruit is trilocular; hence, three seeds are expected per

Percentage Seed set $=\frac{\text { Number of seeds collected }}{\text { Expected number of seeds }} \times \frac{100}{1}$

Data collected in this study were analyzed for significance using $\mathrm{t}$-test and simple linear correlation.

\section{Results and Discussion}

\section{Variation in days to flowering and opening of mature flowers}

There was variation in the number of days to flowering across the five genotypes. IITA-TMS-I011412 was the earliest, producing the first set of flowers at about 2 MAP while the first set of flowers were observed in varieties IITA-TMS-I011368, IITA-TMS-I070539 and IITA-TMS-I30572 after three months of growth. Genotype
COB-7-25 did not flower until 4 months and 10 days after planting (Table 2). The variation in the number of days to initiation of first set of flowers suggests that the trait is genotype dependent, an understanding of which is important in the planning of a flowering synchronization schedule. Shortly after flower initiation in COB7-25, both flower production and branching ceased abruptly and could be attributed to the long periods of drought suffered between November, 2015 and February, 2016 which coincided with the flowering period of the variety. Reduction in branching rate and flowering in cassava as a consequence of water stress has been reported in the past [14].

Table 2: Days to initiation of first flower among the five cassava varieties used as parents in hybridization study in Ibadan in 2015.

\begin{tabular}{|c|c|}
\hline Genotype & Number of Days to Flowering \\
\hline IITA-TMS-I011412 & 65 \\
\hline IITA-TMS-I070539 & 96 \\
\hline IITA-TMS-I01368 & 98 \\
\hline IITA-TMS-I30572 & 102 \\
\hline COB-7-25 & 131 \\
\hline
\end{tabular}

It was observed across the five genotypes studied that plants occupying the border rows flowered earlier than others within the same plot which is an indication that flowering in cassava is strongly 
affected by environmental factors such as temperature, moisture and nutrients, as the border row plants had less competition for sunlight and nutrients relative to plants within the plots. This is in corroboration with the submission of [15] who suggested that flowering in cassava may be strongly influenced by environmental factors; as well as the recommendation by [16] that a spacing of more than $1 \times 2 \mathrm{~m}^{2}$ should be used in establishing crossing blocks to ensure easy hand pollination and give the plants better chance to flower.
The time of the day mature flowers opened also varied among the five varieties re-emphasizing the influence of genotype on flowering in cassava species with flowers on varieties IITATMS-I011368 and IITA-TMS-I070539 opening first followed by IITA-TMS-I011412, COB-7-25 and IITA-TMS-I30572 in that order. This further corroborates earlier submission that information on the time of the day mature flowers open for selected genotypes in a breeding programme is vital for the successful planning of a pollination schedule program in the order of earliness of opening of the flowers [5].

Table 3: Seed set and abortion rates among twenty cassava $F_{1}$ crosses.

\begin{tabular}{|c|c|c|c|c|c|c|}
\hline Populations & NOFP & ENOS & NOFS & NOSC & \% Seed Set & \% Abortion \\
\hline UIC-1 & 118 & 354 & 6 & 15 & 4.2 & 95.6 \\
\hline UIC-2 & 341 & 1023 & 32 & 88 & 8.6 & 90.3 \\
\hline UIC-3 & 28 & 84 & 0 & 0 & 0 & 100 \\
\hline UIC-4 & 441 & 1323 & 32 & 99 & 7.5 & 92.7 \\
\hline UIC-5 & 126 & 378 & 18 & 54 & 14.3 & 85.7 \\
\hline UIC-6 & 71 & 213 & 18 & 53 & 24.9 & 74.6 \\
\hline UIC-7 & 0 & 0 & 0 & 0 & 0 & 0 \\
\hline UIC-8 & 52 & 156 & 5 & 15 & 9.6 & 90.4 \\
\hline UIC-9 & 1 & 3 & 0 & 0 & 0 & 100 \\
\hline UIC-10 & 3 & 9 & 0 & 0 & 0 & 100 \\
\hline UIC-11 & 63 & 189 & 36 & 107 & 57.1 & 42.9 \\
\hline UIC-12 & 236 & 708 & 43 & 128 & 18.1 & 81.8 \\
\hline UIC-13 & 1 & 3 & 0 & 0 & 0 & 100 \\
\hline UIC-14 & 118 & 354 & 47 & 141 & 39.8 & 60.2 \\
\hline UIC-15 & 63 & 189 & 20 & 50 & 26.5 & 68.3 \\
\hline UIC-16 & 76 & 228 & 18 & 54 & 23.7 & 76.3 \\
\hline UIC-17 & 3 & 9 & 1 & 3 & 33.3 & 66.7 \\
\hline UIC-18 & 58 & 174 & 14 & 42 & 24.1 & 75.9 \\
\hline UIC-19 & 91 & 273 & 6 & 17 & 6.2 & 93.4 \\
\hline UIC-20 & 0 & 0 & 0 & 0 & 0 & 0 \\
\hline
\end{tabular}

$\mathrm{UIC}=$ University of Ibadan Cassava; NOFP $=$ Number of flowers pollinated; ENOS $=$ Expected number of seeds; NOFS $=$ Number of fruits set; NOSC $=$ Number of seeds collected.

Populations $11-20$ are reciprocals of populations 1-10 respectively.

\section{Seed set and abortion rate among the F1 hybrids and} their reciprocals

Table 3 shows the percentage seed set among the hybrid populations (UIC1-UIC10) and their reciprocals (UIC11-UIC20) respectively. Out of the 5,670 seeds expected from a total of 1,890 pollinated flowers with 3 possible seeds in each triocular fruit, only 866 seeds were collected, representing $15.3 \%$ of the total which was less than one seed per pollination on the average. This is in agreement with [5] and [17] who recorded low seed set in the populations developed. In this study, the cross IITA-TMS-I011368 $\mathrm{x}$ IITA-TMS-I011412 with the best female and male parents, respectively gave the highest seed set of $57.1 \%$ (Figure 2). This was followed by IITA-TMS-I30572 x IITA-TMS-I011412 (39.8\%), IITATMS-I011368 x IITA-TMS-I070539 (26.5\%), IITA-TMS-I070539 $x$ IITA-TMS-I011412 (24.9\%) and IITA-TMS-I30572 x IITATMS-I011368 (24.1\%) (Table 4). The relatively high percentage 
seed set obtained from these populations in respect to other populations developed in this study suggests that the varieties used as parents in developing the populations are more cross compatible and could ensure relatively higher success in generation of recombinant seeds in cassava breeding programmes. In contrast, $0 \%$ seed set was recorded for population TMS-I01/1412 x COB-

Table 4: Variability in Seed set among populations developed from each cassava parent.

\begin{tabular}{|c|c|c|c|c|c|c|c|}
\hline \multirow[b]{2}{*}{ Female Parent } & \multicolumn{7}{|c|}{ Male Parent } \\
\hline & IITA-TMS-I011412 & IITA-TMS-I011368 & IITA-TMS-I070539 & IITA-TMS-I30572 & $\begin{array}{l}\text { COB } \\
7-25\end{array}$ & Mean & CV\% \\
\hline IITA-TMS-I011412 & $\mathrm{NC}$ & 4.2 & 8.6 & 7.5 & 0 & 5.1 & 33.8 \\
\hline IITA-TMS-I011368 & 57.1 & $\mathrm{NC}$ & 26.5 & 9.6 & 6.2 & 24.9 & 77.5 \\
\hline IITA-TMS-I070539 & 18.1 & 14.3 & $\mathrm{NC}$ & 24.9 & 33.3 & 22.7 & 28.1 \\
\hline IITA-TMS-I30572 & 39.8 & 24.1 & 23.7 & $\mathrm{NC}$ & 0 & 21.9 & 31.4 \\
\hline COB-7-25 & 0 & 0 & $\mathrm{NC}$ & $\mathrm{NC}$ & $\mathrm{NC}$ & 0 & 0 \\
\hline Mean & 28.8 & 10.7 & 19.6 & 14 & 13.2 & 16.6 & \\
\hline CV (\%) & 50.9 & 70.1 & 49.1 & 67.8 & 120.7 & & \\
\hline
\end{tabular}

$\mathrm{CV}(\%)=$ Coefficient of variation; $\mathrm{NC}=$ Not crossed .

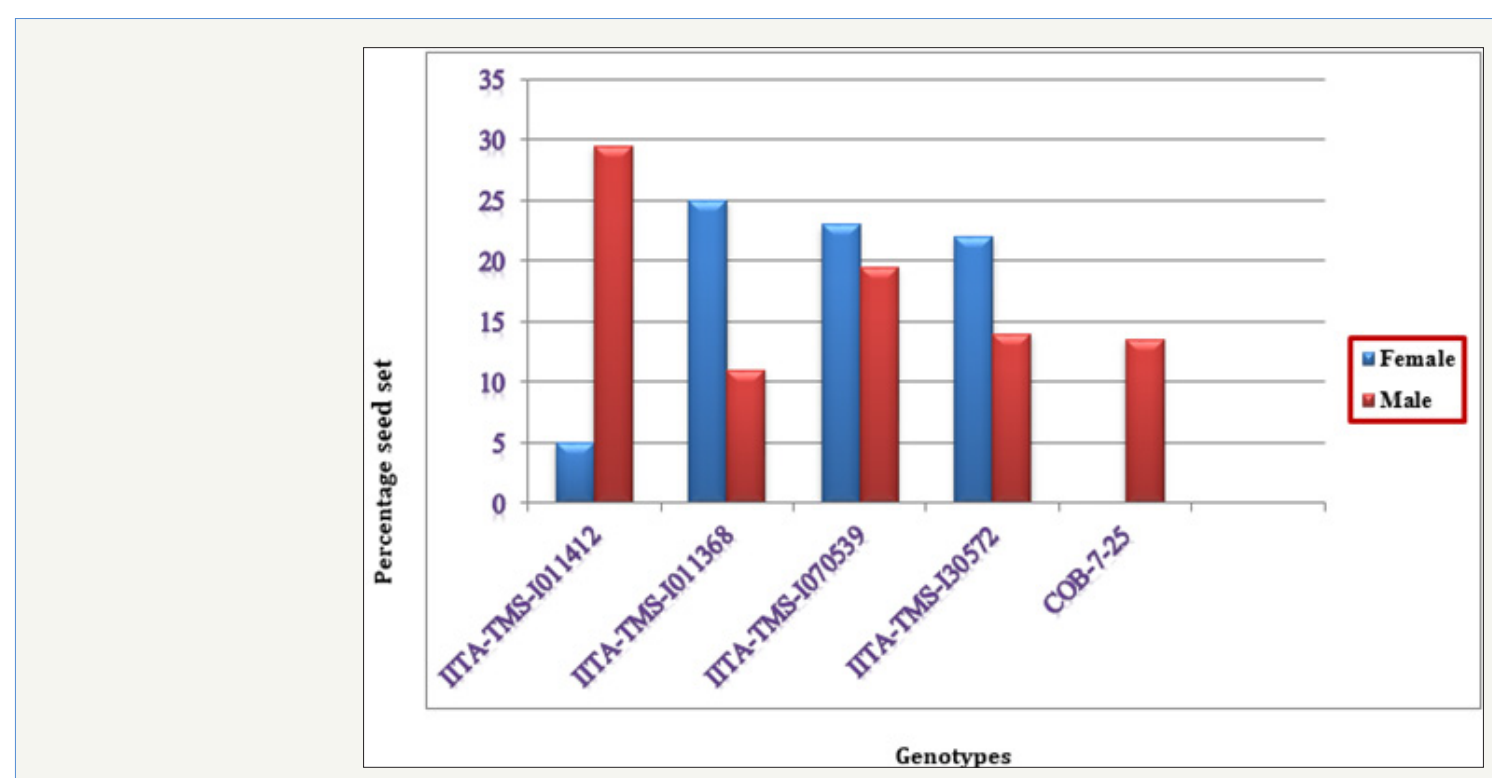

Figure 2: Percentage seed set among populations developed from each parent.

Coefficient of variation was found to be lowest among crosses involving IITA-TMS-I070539 which suggests that seed set is relatively more stable in the parent. However, the wide variation in $\mathrm{CV}$ observed across the clones is an indication of genetic differences among the genotypes for seed set. There was positive $(r=0.65, p$ $=0.17, \mathrm{n}=18$ ) but non-significant correlation between number of flowers pollinated (NOFP) and number of seeds collected (NOSC) among the crosses. This implies that seed set in crosses involving the varieties used in this study cannot be adequately predicted from the number of flowers pollinated. This is in corroboration with submissions of [5] and [17]. Highly significant difference ( $p=0.004)$ was observed for percentage seed set between the $\mathrm{F}_{1}$ crosses and their reciprocals emphasizing that seed set in cassava is influenced
7-25 in this study, an indication of cross incompatibility between the two genotypes. However, conclusions could not be drawn for crosses COB-7-25 x IITA-TMS-I011368, IITA-TMS-I30572 x COB-725 and COB-7-25 x IITA-TMS-I011412 due to the fact that very few flowers were pollinated for each of the crosses.

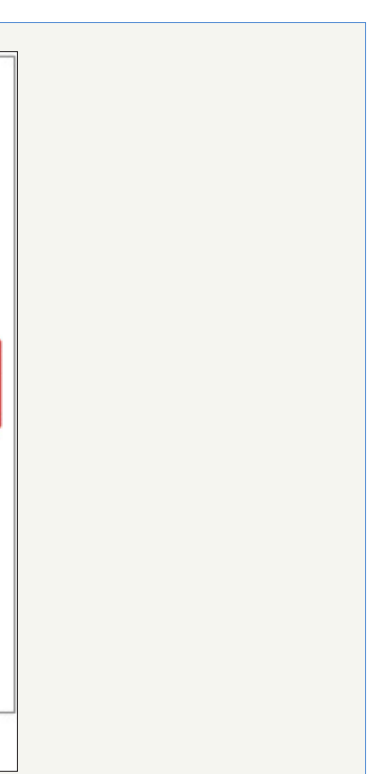




\section{References}

1. Nassar NMA (2007) Wild and indigenous cassava (Manihot esculenta Crantz) diversity: An untapped genetic resource. Genet. Resour. Crop Evol 54(7): 1523-1530.

2. FAOSTAT (2013) Online Statistical Database. Food and Agriculture Organization of the United Nations, Rome, Italy.

3. FAOSTAT (2014) Online Statistical Database. Food and Agriculture Organization of the United Nations, Rome, Italy.

4. Cock JH (1982) Cassava: a basic energy source in the tropics. Science 218(4574): 755-762.

5. Olasanmi B, Akoroda MO, Egesi C, Okogbenin E, Fregene M (2014) Crosscompatibility among six improved cassava (Manihot esculenta Crantz) varieties. Journal of Root Crops 40(1): 15-22.

6. Food and Agricultural Organization (FAO) and International Fund for Agricultural Development (IFAD) (2000) La econom'ra mundial de la yuca. Hechos, tendencias y perspectivas. Fondo Internacional de Desar rollo Agrícola. Organizacio'n de las Naciones Unidas para la Agricultura y la Alimentación, Rome, Italy.

7. Egesi CN, Olasanmi B, Mbanaso ENA, Okogbenin E, Ekwe KC,Fregene $\mathrm{M}$ and Nwosu KI. (2010) Biofortification of cassava for enhanced food and nutrition security. In: Amadi CO, Ekwe KC, Chukwu GO, Olojede A0, Egesi CN (Eds.), Root and tuber crops research for food security and empowerment, National Root Crops Research Institutes, Umudike, Nigeria, pp:151-182.

8. Kawano K (2003) Thirty years of cassava breeding for productivity. Biological and social factors for success. Crop Sci 43(4): 1325-1335.

9. Montagnac JA, Davis CR, Tanumihardjo SA (2009) Nutritional value of cassava for use as a staple food and recent advances for improvement. Comprehensive Rev Food Sci Food Safety 8(3): 181-194.
10. Aguayo VM, Baker SK (2005) Vitamin A deficiency and Child survival in sub-Saharan Africa. A reappraisal of challenges and opportunities. Food Nutr Bul 26(4): 348-355.

11. Rodriguez-Amaya DB, Kimura M (2004) Harvest Plus handbook for carotenoid analysis. Harvest Plus Technical Monograph Series 2, International Food Policy Research Institute (IFPRI), Harvest Plus, Washington DC, USA.

12. Liu D, Zhang H, Zhang L, Yuan Z, Hao M, et al. (2014) Distant Hybridization: A Tool for Interspecific Manipulation of Chromosomes. Pratap and Kumar (Eds.), Volume 1, Alien Gene Transfer in Crop Plants, Innovations, Methods and Risk Assessment, Springer Science + Business Media, New York, USA.

13. Acquaah G (2012) Principles of plant genetics and breeding. ( $2^{\text {nd }}$ edn), John Wiley and Sons Ltd, New York, USA, pp: 131-145.

14. Connor DJ, Cock JH, Parra GE (1981) Response of cassava to water storage. Field Crops Resources 4:181-200.

15. Taylor N (2005) Cassava (Manihot esculenta Crantz): Reproductive biology and practices for confinement of experimental field trials. In: Chavarriaga-Aguirre P, Halsey M (Eds.), Report prepared for the Program for Biosafety Systems, Washington DC, USA

16. Kawano K (1980) Cassava. In: Hybridization of Crop Plants. America Society of Agronomy, Crop Science Society of America, Madison, WI, pp: 217-225.

17. Njoku DN, Ikeogu UN, Ewa F, Egesi C (2015) Crossability and germinability potentials of some cassava (Manihot esculenta Crantz) progenitors for selection. Journal of Plant Breeding and Crop Science 7(3): 61-66
Creative Commons Attribution 4.0

International License

For possible submissions Click Here

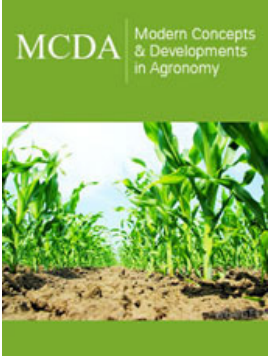

Modern Concepts \& Developments in Agronomy

\section{Benefits of Publishing with us}

- High-level peer review and editorial services

- Freely accessible online immediately upon publication

- Authors retain the copyright to their work

- Licensing it under a Creative Commons license

- Visibility through different online platforms 